\title{
Mythopoetic imagination as a source of critique \\ and reconstruction: alternative storylines \\ about our place in cosmos
}

Heikki Patomäki

University of Helsinki

\begin{abstract}
Temporal reflexivity requires that we recognize consciousness, society and history as mythopoetically constituted. Mythopoetic imagination can also be a means of critique of the prevailing myths. In complex pluralist societies, there are hegemonic struggles over constitutive myths, shaping both our explanatory accounts of the past and scenarios about possible futures. A widespread myth of contemporary liberal-capitalist societies comprises three temporal tiers: deep cosmic scepticism; various ethical and political lessons drawn from, and theories related to, this scepticism; and the capacity of technology and economic growth to bring us some comfort and enjoyment in our short lives. An alternative cosmic storyline centres on the prospects of life and culture, rather than death, and on our common evolvement also through collective learning. In this paper, I examine possible interpretations of the basic Big History (BH) narrative in view of these two ideal-typical storylines. How is BH positioned and positioning itself in relation to the main scientific myths of the 21 st century? I assess the plausibility of $\mathrm{BH}$ in terms of both logos and mythos; and criticising BH's ambiguities, I argue in favour of the life-oriented storyline.
\end{abstract}

Correspondence | Heikki Patomäki, heikki.patomaki@helsinki.fi

Citation | Patomäki, H. (2019) Mythopoetic imagination as a source of critique and reconstruction: alternative storylines about our place in cosmos. Journal of Big History, III(4); 77 - 97.

DOI | https://doi.org/10.22339/jbh.v3i4.3433

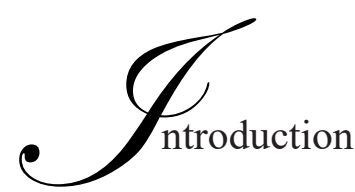

Big History $(\mathrm{BH})$ is about developing a creation myth and origin story suitable to our globalized world characterised by (i) economic growth and ecological deterioration and (ii) by the existence of weapons of mass destruction and other risks. The idea is that this story must and can accord with modern science and its findings. The story must also be open to critique, revision and improvement. So far, the starting point has been that the Big Bang cosmology provides us with a scientific creation myth. The metatheory of emergence and complexity fills in the rest of the story. ${ }^{1}$

1 David Christian, Maps of Time: An Introduction to Big History (Berkeley: University of California Press, 2004), especially $1-20,505-511$. The basic idea is summarized neatly in a 2014 textbook: "[...] there is a single thread that runs through the whole story: the emergence, over the 13.8 billion years since the universe appeared, of more and more complex things. Complex things have many diverse components that are arranged in pre-
A difficulty is that modern science has been set against all myths. The standard modern meaning of myth has been that of a narrative that has no basis in reason and cannot be true. Mythos is opposed to logos. It is well known that Giambattista Vico argued already in the early $18^{\text {th }}$ century that human civilization is based on the emergent capacity to imagine, through complex language, and thus to create something new. ${ }^{2}$ Since the time when humans transcended basic physical impulses with the help of language, we have

cise ways so that they generate new qualities. We call these new qualities emergent properties". David Christian, Cynthia Stokes Brown, and Craig Benjamin, Big History: Between Nothing and Everything (New York: McGraw-Hill Education, 2014), 4. For a systematic theoretical exposition of emergence as combogenesis and of twelve major steps of emergence, see Volk, Tyler, Quarks to Culture. How We Came to Be (New York: Columbia University Press, 2017).

2 See e.g. Joseph Mali, The Rehabilitation of Myth: Vico's 'New Science' (Cambridge: Cambridge University Press, 2002). 
been making our own cultural and social worlds.

Consciousness, society and history are mythopoetically constituted. If a myth is lived by people in their everyday practices and institutions, the resulting social order testifies to the truth of that myth. Hence, in order to know the human world, we must know its constitutive myths. For Vico, mythos and logos are mutually implicated. The Vicoan viewpoint needs to be rephrased, however, in terms of critical human sciences and epistemological, ethical and political pluralism. Critical science implies that beliefs can be wrong, even when they are constitutive of actions, practices and institutions. Pluralism means deep respect for other points of view, without relativism. As Nicholas Rescher explains:

There is no good reason why a recognition that others, circumstanced as they are, are rationally entitled in their circumstances to hold a position at variance with ours should be construed to mean that we, circumstanced as we are, need feel any rational obligation to abandon our position. In so far as one is rational (and no doubt not all of us are) one cannot see the alternatives as indifferent. ${ }^{3}$

Temporal reflexivity sensitises us to recognize that the constitution of consciousness and society occurs also mythopoetically. ${ }^{4} \mathrm{I}$ argue in this paper

3 Nicholas Rescher, Pluralism. Against the Demand for Consensus (Oxford: Oxford University Press, 1993), 119-20.

4 Reflective consciousness, which has enabled our current levels of social complexity, can be seen as an emergent power made possible by the evolvement of metaphors and mental language and related social complexity rather late in human history (perhaps as late as during the Axial Age). This hypothesis may be controversial, but seems to me a plausible way of accounting for the existing archaeological and early historical evidence; Julian Jaynes, The Origin of Consciousness in the Break-Down of the Bicameral Mind (Boston: Houghton Mifflin, 2000). For an alternative account of roughly the same change, see Iain McGilchrist, The Master and His Emissary (New Haven CT: Yale University Press, 2012), 260-6. Tyler, Quarks to Culture, 117-119 [note 1] that to be rational, the stories we are telling, involving anticipations of possible futures, must be open to criticism and revisable in a systematic fashion. Mythopoetic imagination can also be a means for critique of prevailing myths. ${ }^{5}$ In complex pluralist societies, there are hegemonic struggles over constitutive myths, shaping both our explanatory stories about the past and scenarios about possible futures. ${ }^{6}$ These myths can be addressed in various ways (empirical, theoretical etc) and at various levels of abstraction.

At the heart of $\mathrm{BH}$ is the common modern idea that with the development of science, God has been moved further and further away from the story of the origins of the cosmos (not to speak of causal interventions in it). ${ }^{7}$ From this starting point different stories have been developed. I argue that a basic underlying myth of contemporary liberal-capitalist societies consists of three temporal tiers: deep cosmic scepticism if not desperation; various lessons drawn from this scepticism and related ideologies, such as Darwinism ${ }^{8}$;

and Yuval Noah Harari, Sapiens. A Brief History of Humankind (New York: HarperCollins, 2014), ch 2, locate the origin of full language earlier than Jaynes $(70,000-30,000$ BCE rather than $25,000-15,000)$, but do not distinguish between full language and metaphorical language.

5 Chiara Bottici, A Philosophy of Political Myth (Cambridge: Cambridge University Press, 2007).

6 Robert W. Cox, Approaches to World Order (Cambridge: Cambridge University Press, 1996), e.g. 131.

7 Christian, Maps of Time, 22 [note 1]; thus God may be unlikely to frame $21^{\text {st }}$ century debates about political theory, although this is an open question; see e.g. Heikki Patomäki, "From East to West: Emergent Global Philosophies - Beginnings of the End of the Western Dominance?," Theory, Culture \& Society 19 no. 3, (2002), 89-111.

8 Darwin's theory of evolution is subject to many interpretations and it has been adopted to diverse purposes. It may be stressed that 'the struggle for existence' often brings about adverse consequences and is thus not good as such; or that 'survival of the fittest' is not the only mechanism of evolution but rather evolution is also about emergence of new forms of complexity. It may also be argued that when applied to society the mutation and selection conditions are social and more Lamarckian than Darwi- 
and the capacity of technology and economic growth to bring some comfort and enjoyment to our short lives. An alternative cosmic storyline centres on the prospects of life, rather than death, and on the promises of our common evolvement also through learning. In my ideal-typical schemes, I associate these life- and learning-oriented ideas with pragmatism and critical realism, although many of these alternative notions are shared much more widely. ${ }^{9}$ On the basis of the two ideal-typical storylines, I examine, compare and assess claims made within $\mathrm{BH}$ in terms of their scientific (logos) and narratological (mythos) plausibility. I show the ambiguities of the current $\mathrm{BH}$ narrative and envision a way forward.

\section{On the narrative dimension of scientific explanations and futures scenarios}

Temporality is fundamental to social actions and scientific explanations alike. According to Paul Ricouer, there is a unity of having-been, comingtowards and making present, since these are thought and acted upon together by the actors. This is the

nist. In this paper I purposefully associate Darwinism almost exclusively with those doctrines that tend to reduce evolution to 'struggle for survival' or something analogical and either accept this mechanism as 'natural' also in society (or as given in some other manner) or elevate it to a principle that generates normative good or 'optimal' outcomes (for instance free market doctrines).

9 In this paper pragmatism is largely associated with Charles Peirce and William James and their followers; and critical realism is associated with Roy Bhaskar and the network of scholars who have been active in the International Association of Critical Realism (IACR). I rely more on the latter than the former, but there are many commonalities between the two. It is also important to bear in mind that concepts such as emergence, causation, learning and normativity are best understood as open sites of discussions and developments, neither originating nor ending in any particular philosophy or theory. Instead of giving a long list of sources, I cite a specific article making the point that pragmatism covers much of the same ground as critical realism: Inanna Hamati-Ataya, "Beyond (Post)Positivism: The Missed Promises of Systemic Pragmatism," International Studies Quarterly 56, no. 2 (2012), 291-305. temporality of practical experience and action. The making-present of practical action stems from the anticipation of possibilities of transformative action producing outcomes on the basis of understanding of that which has-been (history). The horizon of action is thus inherently temporal. ${ }^{10}$ Many political projects derive their motivation from the sense they render to our/their lives. Moreover, the appeal of grand narratives tends to be reinforced by awareness of one's own mortality. ${ }^{11}$

Scientific explanations too have a temporal dimension. A researcher draws a meaningful story from a diversity of temporal events that are constitutive of episodes and processes. Emplotment combines two temporal dimensions. By stipulating causal hypotheses, one captures the episodic dimension of temporality and creates components of explanation that go beyond mere chronicle. By grasping together the whole of the episode, one constructs a narrative or a story proper, a story which has a counterfactual sense of ending. As processes continue and history remains open, this sense of ending must be artificially created (the end is unreal as processes continue).

Every scenario is a story which has motivating power or charisma because it gives (or fails to give) meaning to the lives of individuals, groups and/or humankind. It is therefore very important to recognise the deep structures in our culture according to which we tell stories and construct myths. Structures of meaning determine capacity to generate stories. Structures of meaning may be relatively enduring and widely shared across cultures, even though they are subject to cultural variations, historical change and learning. When put together, lesser-scale stories may presuppose or form a grand or cosmic narrative of the origins, possibilities

10 Paul Ricoeur, Time and Narrative Vol.1, trans. Kathleen McLaughlin and David Pellauer (Chicago: The University of Chicago Press, 1984), 68-84.

11 See Hayward Alker, Rediscoveries and Reformulations: Humanistic methodologies for International Studies (Cambridge: Cambridge University Press, 1984), e.g. 105, 269-70. 
and outlook for humankind. Every grand story locates the present context as part of a wider and structured temporal whole, thus organising our anticipations of possible futures at different scales of time. In our practical understandings and actions, grand stories become part of the Ricouerian triad of having-been, coming-towards and making present. Grand stories are in effect myths, i.e. "sacred" narratives explaining how the world and humankind came to be in their present form and what their future possibilities are.

Value-laden narratives affect our perceptions also in scientific contexts. The claim that scientific expert opinion is driven by sense-making and storytelling is evident in human sciences ${ }^{12}$, but it is true also for natural sciences ${ }^{13}$. The plausibility of theories, successful tests, or predictive success do not unequivocally determine rational adoption of theories in sciences, not even in physics or chemistry (although many established textbook-level theories are rightly seen as being beyond reasonable doubt in the sense that they have passed all tests and work well for practical purposes).

The scientific process involves debates about cognitive values and philosophical theories. Cognitive values and philosophical theories are connected to our worldview more generally. This indicates that sense-making and story-telling is part of science, too, although many scientists do not pay enough attention to the philosophical, religious or ideological implications of their theories. Like any hypothesis, a hypothesis concerning emplotment should be made vulnerable to refutation and qualification, and open to the probative force of empirical evidence. The narrative hypothesis involved in scientific explanations and

12 E.g. Philip E. Tetlock, "Theory-Driven Reasoning about Plausible Pasts and Probable Futures in World Politics: Are We Prisoners of Our Preconceptions?," American Journal of Political Science 43, no. 2 (1999), 335-66.

13 See e.g. Larry Laudan, Science and Values: The Aims of Science and Their Role in Scientific Debate (Berkeley, CA: University of California Press, 1984). anticipations can be tested by various empirical and conceptual means. Do the elements of the story and their order correspond to what really has happened, is happening, or will happen? Hypotheses can be also tested at a more generic level, in terms of coherence and conceptual and theoretical plausibility, or in terms of their existential hypotheses (e.g. do the assumed entities, relations and mechanisms really exist?). Hypothesis-testing is not mechanistic, but requires interpretation and situated judgement. ${ }^{14}$

Because of the dependence of hypothesis-testing on interpretation and judgement, what is required is a strong ethics of scientific research. The basic realist manifesto is that "as scientists, that is members of a certain community, we should apportion our willingness or reluctance to accept a claim as worthy to be included in the corpus of scientific knowledge to the extent that we sincerely think it somehow reflects the way the world is" ". Science follows critical public procedures of verification and falsification, which are different from those of mere speculative imagination.

Yet scholars are also involved in the (re)production of social realities. As there can be no single decisive tests between theories, rationality and openness to learning become ethical and political matters also in a sense that goes beyond the mere virtue of truth. This point has to do with the ontology of time and temporality. The past is, in part, undetermined, and at some level will remain so. The meaning and characteristics of an event, episode or process depend on how the relevant processes turn out. For the same

14 A further complication is that it is possible that the same material can be ordered according to different actual or potential terminal consequences. All these temporal interpretations can be true with regard to the causal powers and sequences upon which they are elaborated. There may thus be many coherent and plausible stories to tell on the basis of the same material. See Heikki Patomäki, After International Relations: Critical Realism and the (Re)Construction of World Politics (London: Routledge, 2002), 141.

15 Rom Harré, Varieties of Realism: A Rationale for the Natural Sciences (Oxford: Basil Blackwell, 1986), 89. 
reasons, we must rely on future-oriented narratives to describe contemporary events and on-going processes, the end of which can only be seen from a vantage point later than the moment of reflection or action within that process. ${ }^{16}$

The future, in turn, can only be studied in terms of scenarios of possible and likely futures. The future is real but not yet determined and our activities -including scholarly activities - take part in co-determining future events and episodes, potentially shaping processes at various scales of time. ${ }^{17}$ Processes are open-ended and flowing, with one process capable of sliding into another, and with smaller processes combining to form larger processes. Reflexive involvement implies also ethical and political responsibility. The recognition of our ethical responsibility about the choice of stories is compatible with the scientific realist manifesto.

\section{The basic mythologems of modern liberal-capitalist societies}

In both natural and human sciences, the more canonical or dramatic the outcome of the story, the more appealing the story usually becomes. We know from psychological and social-psychological studies that missing links are quickly filled in with elements adopted from the pre-existing mythical and ideological scripts. More often than not, anticipations based on simple canonical or dramatic stories vastly inflate the likelihood of the expected course of events and processes. ${ }^{18}$ Misleadingly canonised, generalised and

16 For a fuller account, see Heikki Patomäki, "On the Complexities of Time and Temporality: Implications for World History and Global Futures," Australian Journal of Politics and History 57, no. 3 (2011), 339-52.

17 See also Heikki Patomäki, "Praxis, Politics and the Future: A Dialectical Critical Realist Account of World-Historical Causation," Journal of International Relations and Development 20, no. 4 (2017), 805-25.

18 Thomas Gilovich, How We Know What Isn't So: The Fallibility of Human Reason in Everyday Life (New York: The Free Press, 1991); Philip E. Tetlock, Expert Political Judgement: How inflated stories can serve as constitutive mythologem of a given social order (within which researchers operate), though they are also contested.

Arguably, the basic myth of liberal-capitalist societies of the late 20th century and early 21 st century comprises three mythologems and temporal tiers: (i) the first tier is constituted by cosmic myths of desperation, involving the Copernican principle - "we don't occupy a privileged position in the universe" 19 - and various narratives about how the story of humanity will inevitably end up in death, at some scale of time ${ }^{20}$; (ii) the second tier is motivated by cosmic desperation and involves a conviction that the spheres of life and culture either are or should be highly competitive, resulting in Darwinist or promarket theories and ideologies ${ }^{21}$; (iii) the third tier

Good Is It? How Can We Know? (Princeton: Princeton University Press, 2005), chs 2 and 3.

19 Astrophysicist Brandon Carter, in his contribution to a 1973 symposium honouring Copernicus's 500th birthday, criticised over-reliance on the Copernican principle: "Although our situation is not necessarily central, it is inevitably privileged to some extent". Brandon Carter, "Large Number Coincidences and the Anthropic Principle in Cosmology," in Confrontation of Cosmological Theories with Observational Data, ed. Malcom Longair (International Astronomical Union, 1974), 291-8, accessed July 11, 2018, http://adsabs.harvard.edu/abs/1974IAUS...63..291C.

20 German scientist Rudolph Clausius claimed in the 1860s that everything will end in "heat-death" (Wärmetod). The second law of thermodynamics says roughly that entropy within closed systems should gradually become maximal and disorder should eventually reign. Entropy is a measure specifying the amount of disorder or randomness or something similar in a system that contains energy or information. Despite the confidence of Western scientific establishment in the truth of this gloomy cosmic story, the meaning and scope of the second law is ambiguous. Entropy has many meanings and we do not even know whether cosmos is a closed system. For a critical discussion on the development of the second law of thermodynamics, see Peter A. Corning and Stephen Jay Kline, "Thermodynamics, Information and Life Revisited, Part I: 'To Be or Entropy'," Systems Research and Behavioural Science 15, no. 4 (1998), 273-95.

21 In popular imagination, this mythologem is evident for instance in fictions about encounters with extra-terrestrial others depicted as evil beasts. In these stories, ETs are either as slaves 
consists of belief in the blessings of technological progress and economic growth generated by capitalist market economy, providing sources of enjoyment and pleasure to us humans in our - and perhaps also in our children's - lifetimes. ${ }^{22}$

These ideas have deep philosophical roots. The allegedly value-neutral technical methods of empiricist science entail thorough scepticism about anything metaphysical or normative. God or values have no place in science. In the $18^{\text {th }}$ century, David Hume explained that we should trust only our sense perceptions and be sceptical of anything else such as religious texts. ${ }^{23}$ The sceptical sentiment grew stronger in the $19^{\text {th }}$ century. Friedrich Nietzsche was among the first to fully articulate the devastating impact of empirical science on culture and civilization. ${ }^{24} \mathrm{God}$ is dead! We are alone on this insignificant planet. Nietzsche proclaimed further that no universal perspective is possible. Christianity, Kantianism, and

of their passions or mindless followers of their genetically programmed codes of behaviour, independently of how technologically advanced they may be. For a critical analysis, see Heikki Patomäki, "Dialectics of Civilizations: A Cosmic Perspective," in Alker and IR: Global Studies in an Interconnected World, ed. Renée Marlin-Bennett (London: Routledge, 2008), 87-101.

22 Recently, this optimistic tier of the liberal-capitalist worldview has been defended by Steven Pinker, Enlightenment Now. The Case for Reason, Science, Humanism and Progress (London: Penguin Books, 2018); and Hans Rosling (with Ola Rosling \& Anna Rönnlund) Factfulness: Ten Reasons We're Wrong about the World - And Why Things Are Better than You Think (London: Sceptre, 2018).

23 Hume was not consistent in his attitude towards religion or morality; he also wrote things like "the whole frame of nature bespeaks an intelligent author"; quoted in John C.A. Gaskin, "Hume on Religion," in The Cambridge Companion to Hume, ed. David Fate Norton (Cambridge: Cambridge University Press, 1993), 320. Although the fear of censorship and consequences might have led Hume to write contradictory statements, as a consistent sceptic Hume was unable and unwilling to deny the existence of God.

24 For Nietzsche's three phases and his diverse and ambivalent pursuits, see Maudemarie Clark, "Nietzsche, Friedrich," in The Shorter Routledge Encyclopedia of Philosophy, ed. Edward Craig (London: Routledge, 2005), 726-41. utilitarianism are mere slave-moralities; we should be looking for something better. What is coming in the history of the next two centuries is the "advent of nihilism". ${ }^{25}$ What Nietzsche really meant has been a source of endless discussions, but his prophetic texts clearly stress the nihilistic undercurrents of empirical science and modernity.

Contemporary cosmic myths of desperation are told in terms of theories of astrophysics, chemistry and theory of evolution. Nothing really matters, because most of things we see and experience are ultimately mere illusions. Even time and causation are not really real. Rather, the world is atemporal and mathematical. Usually only claims that can be expressed in the language of mathematics are truly scientific. The language of mathematics is technical, neutral and value-free.

Moreover, the origin of everything, the Big Bang, is itself a meaningless event. It may well be that numerous black holes produce new universes; or alternatively the universe may have emerged from nothing at all, for instance due to arbitrary quantum effects. The universe as a whole may be moving towards a heatdeath or some other ultimate end-as-death, perhaps due to the ever-accelerating expansion of space. But also in shorter scales of time, the end looks inevitable. The solar system will come to an end with the lifecycle of the Sun; the Sun may collide with some other cosmic object; and the Earth may have only 500 million years left in the habitable zone of the system. Meanwhile, our planet seems constantly vulnerable to all sorts of cosmic and internal natural catastrophes. Finally, it seems increasingly likely that we humans will destroy ourselves already in the course of the $21^{\text {st }}$ century. ${ }^{26}$ The story is basically the same epic tragedy - without heroes - at all scales of time, from cosmic

25 Friedrich Nietzsche, The Will to Power, trans. Walter Kauffman and Reginald John Hollingdale (New York: Vintage, 1968), 3.

26 Martin Rees, Our Final Century: Will Civilisation Survive the Twenty-First Century? (London: Arrow Books, 2004). 
to human.

Empiricism (positivism) relies on instrumentalism about knowledge. Knowledge is seen as something that can be used to control the world. Cosmic desperation associated with empiricist philosophical doctrines encourages short-termism and technical and preference-maximising orientation to the world. Moreover, empiricism tends to go hand in hand with reductionism (e.g. physicalism, biologism, individualism). ${ }^{27}$ Repeatedly cosmic desperation has been connected with Darwinist ideologies, although desperation may also trigger an existentialist commitment to any ideology - such as nationalism or statist socialism - providing at least some hope about a better world, however unrealistic that may be given the underlying premises. ${ }^{28}$ Most characteristically, however, the modern cosmic myths of desperation and their sceptical and empiricist underpinnings have

27 For a consistent empiricist, what exists is "my sense-experiences". The objects of these sense-experiences are atomistic events. Other perceiving individual minds may be allowed to exist as well. This kind of empiricist ontology encourages epistemological reductionism (e.g. physicalism, biologism, individualism). For example in neoclassical economics, there is a tendency to reduce macroeconomics to microeconomics focussing on individual decision-makers; to use psychology to explain why individuals are what they are; and to use socio-biology to explain psychology.

28 An interesting case is Louis Althusser, whose commitment to the true meaning of Marx's theory, his "anti-humanism", and his loyalty to the Communist Party despite its hierarchies, exclusions and violence can be read as an existentialist ethico-political commitment in an otherwise nihilist world. Five years after killing his wife, Althusser wrote memoirs where he exclaims his desperation and repeats, in a Freudian language, many of the points made by Nietzsche, "Does one have to point out that, in addition to the three great narcissistic wounds inflicted on Humanity (that of Galileo, that of Darwin, and that of the unconscious), there is a fourth and ever graver one which no one wishes to have revealed (since from the time immemorial the family has been the very site of the sacred and therefore of power and of religion). It is an irrefutable fact that the Family is the most powerful ideological State apparatus." Louis Althusser, The Future Lasts Forever: A Memoir, trans. Richard Veasey (New York: The New Press, 1993), 104-105. supported ideas about competition of individuals and firms as the foundation of modern market society. ${ }^{29}$ Scepticism, combined with the reduction of the necessary and the possible to the actual, generates among other things 'there is no alternative' thinking ${ }^{30}$ and the tendency to write Whig-histories about the inevitable progress towards the present ${ }^{31}$. Reductionism suggests either value subjectivism (though individuals may of course behave morally for whatever arbitrary reasons) or outright moral nihilism.

\section{A critique of the prevailing mythologeme: there is an alternative}

From a methodological point of view, the prevailing

29 This attitude is formalized in mainstream neoclassical economics, which revolves around the concept of "perfect competition". Ben Fine summarizes its development: "[All t]his was done through an extraordinary reductionism in which all else was sacrificed in order to obtain the desired results, an implosion of homo economicus upon itself". Ben Fine, "Neoclassical Economics: An Elephant Is Not a Chimera but Is a Chimera Real," in What Is Neoclassical Economics? Debating the Origins, Meaning and Significance, ed. Jamie Morgan (London: Routledge, 2015), 186.

30 As Roy Bhaskar explains: "Ontological reductionism transposed to the human zone has particularly damaging consequences. In perfect resonance with the empiricist concept of science as a behavioural response to the stimulus of given facts and their constant conjunctions, society is conceived as composed of individuals, motivated by given desires and conjoined (if at all) by contract. Reason is reduced to the ability to perform an optimizing or satisficing operation and freedom consists in its unimpeded exercise. [....] It is the ideology of the market place and more generally of the established order of things, of TINA (there is no alternative)." Roy Bhaskar, Reclaiming Reality: A Critical Introduction to Contemporary Philosophy (1989; repr., London: Routledge, 2011), 10.

31 Herbert Butterfield developed this concept in his The Whig Interpretation of History (London: G.Bells \& Sons, 1959, orig. published 1931). According to Butterfield, the Whig history leads very quickly to the division of the world into supporters and opponents of the story of progress toward the present, goodies and baddies, and the narrative of heroes from this perspective. Pinker and Rosling, mentioned in note 22, are contemporary examples of Whig-histories. 
scientific stories about the ultimate fate of humanity seem to involve various fallacies and misleading assumptions. Most common are (i) the assumption of closed systems and (ii) overconfidence on the currently prevailing scientific theories. Both are rooted in the empiricist (positivist) philosophy of science, which is moreover self-nullifying in denying causal agency and its role in science. ${ }^{32}$ Moreover, over-reliance on mathematics can further feed the sense of certainty encouraging dogmatism.

In reality, systems are open. Open systems interact with causal processes not confined within them and often involve qualitative changes and emergence. The openness of systems means that everything is historical and evolving, (possibly) including even the laws of physics. New constellations, properties and powers can emerge. Moreover, science is historical, processual and open-ended. It is dependent on the antecedently established facts and theories, paradigms and models, methods and techniques of inquiry. For a particular scientific school or scientist, these provide the material from which new ideas, theories etc are forged. On that basis researchers produce - in a particular geohistorical context - new facts and theories, paradigms and models. The process of scientific change does not leave earlier conceptualisations intact. Something is lost and something new is created. ${ }^{33}$ In some sense Newtonian mechanics may describe a special case of the theory of relativity, but the latter includes also a novel conception of space-time (in general relativity, the effects of gravitation are ascribed to spacetime curvature instead of a force). The ultimate nature of space and time remains disputed in contemporary science.

Many contemporary scientists proclaim that there is nothing special about this universe of ours. It is a mere

32 See Roy Bhaskar, Scientific Realism and Human Emancipation (London: Routledge, 2009), 8, 16-19, 32, 71, 153.

33 For a deeper and more sophisticated account, see Bhaskar, Scientific Realism, 47-62 [note 32]. result of a cosmic lottery or some sort of Darwinist selection. There are countless (if not an infinite number of) disconnected universes; this one of ours just happens to be life-friendly, and only for the time being. ${ }^{34}$ The process of biological evolution is arbitrary; humanity is an accidental outcome. A key problem with speculations about cosmic selection or lottery is that these presuppose the existence of something that probably can never be observed. Thereby they also radically multiply beings, thus violating even the most cautious and qualified interpretation of Ockham's razor (to which empiricism and positivism are committed). ${ }^{35}$ Although it is in principle possible that this line of line of research will yield falsifiable hypothesis at some point, a further problem is that failure to verify predictions can be easily explained away at no cost to the speculation, given the indirect nature of possible hypotheses. ${ }^{36}$ Application of the Copernican principle or Darwinism to speculative universes can thus be misleading. A risk of relying on speculations about countless universes is that science comes to be replaced, quite unreflexively, with stories derived merely from traditional myths and ideology.

We can now start to see why scenarios about an inevitable end-in-death are rather implausible from a scientific point of view, however appealing as stories (according to Isaac Asimov "the conviction that the whole universe is coming to an end $[\ldots]$ is an old one, and is, in fact, an important part of Western tradition" ${ }^{37}$ ). Scenarios about what will happen in

34 For different but insightful discussions, see for instance Paul Davies, The Goldilock's Enigma: Why is the Universe Just Right for Life? (London: Allen Lane, 2006), ch. 8; Martin Rees, Before the Beginning: Our Universe and Others (London: Simon and Schuster, 1997), 251-69; Leonard Susskind, 2006. The Cosmic Landscape: String Theory and the Illusion of Intelligent Design (New York: Little, Brown and Co., 2006), 293-376.

35 See Heikki Patomäki, "After Critical Realism? The Relevance of Contemporary Science," Journal of Critical Realism 9, no. 1 (2010), especially n. 81, 83-4.

36 Lee Smolin, Time Reborn (London: Penguin Books, 2014), 250.

37 Isaac Asimov, A Choice of Catastrophes: The Disasters that 


\section{Empiricism / positivism / Nietzsche}

- Value-neutral technical methods of empiricist science $\rightarrow$ skepticism about anything metaphysical or normative, but often scientist certainty about science.

- God is dead! We are alone on this insignificant planet!

- Knowledge is a tool of control and power.

- Changes are non-real, illusionary or minimal.

- Reductionism $\rightarrow$ tendency toward atomism.

- Reason is reduced to the ability to perform an optimizing or satisficing operation; and freedom consists in its unimpeded exercise.

\section{Critical realism / pragmatism}

- Open systems $\&$ emergence is real $\rightarrow$ history is open-ended

- science itself is an open-ended process

- Everything is historical and evolving, including our agency, will and intentions

- rationality is normative $\&$ things matter $\rightarrow$ ethical and political learning

- Freedom can be increased by replacing unnecessary (and often misrepresented) sources of causal determination with more wanted and needed sources

- self-determination - good life

- History is not meaningless; the rational telos of history is dialogical and evolves with history.

- Change \& emergence in world society: transformative political agency.

Table 1: Ideal-typical philosophical differences (logos)

the next thousands, millions, or billions of years are speculative and the more so, the further we reach. There are two reasons for this: the openness of systems (ontology) and the open-ended nature of the process of scientific learning (epistemology). There are thus ontological limits to the predictability of cosmic futures. Epistemologically, the purpose of science is not to produce timeless dogmas; rather science is an open-ended process characterised by differences of opinion, pluralism and learning. In both ways, the future is open. ${ }^{38}$

The tacit assumption of projecting long-term futures on the basis of currently accepted scientific theories

Threaten Our World (London: Arrow Books, 1981), 13.

38 Systems are always open and closed only to a degree. Future can be analysed in terms of conditional and more or less likely possibilities of becoming. The closer we get to a given point in the future, the more shaped and structured it is. Moreover, it is possible to assess the intersubjective-qualitative probability of different scenarios and revise our scenarios in light of new evidence and developments. Heikki Patomäki, "Exploring Possible, Likely and Desirable Global Futures: Beyond the Closed vs. Open Systems Dichotomy," in Scientific Realism and International Relations, ed. Jonathan Joseph and Colin Wight (Palgrave: London, 2010), 147-166. is that time will leave those theories intact. Many scientists seem unable or unwilling to take on board the lessons of the history of science as a changing and evolving social practice, to see themselves as part of a long process of scientific developments. However, in a mere $1 / 1000^{\text {th }}$ of a million years our science and technology is bound to look very different. Just imagine how our science and technology will look, say, in the $32^{\text {nd }}$ century. The future developments are likely to accord with Arthur C. Clarke's famous three laws ${ }^{39}$ :

1. When a distinguished but elderly scientist states that something is possible, she is almost certainly right. When she states that something is impossible, she is very probably wrong.

2. The only way of discovering the limits of the possible is to venture a little way past them into the impossible.

39 Discussed in Arthur C. Clarke, "Hazards of Prophecy: The Failure of Imagination," in Profiles of the Future: An Inquiry into the Limits of the Possible (London: Indigo, 2000), 19-26. 
3. Any sufficiently advanced technology is indistinguishable from magic.

When new scientific possibilities are opened up and new advanced, "magic-like" technologies developed (enabling also new paths of research), scenarios about our cosmic fate at different scales of time are very likely to change.

\section{An alternative mythologeme: the power of life and culture}

It is possible to use our imaginative capacities to develop alternative and scientifically and mythopoetically more plausible storylines. ${ }^{40}$ In this section, I present a life- and culture-oriented storyline that accords at least as well with the findings of contemporary science as the liberal-capitalist storyline. Similarly to the latter, the alternative can be understood as an attempt to build a coherent and plausible story out of somewhat diverse elements, that is, as an ideal-type.

To begin with, the currently standard version of the Big Bang theory is unlikely to be the last word. The homogeneity of the cosmic background radiation is habitually interpreted as evidence for a singularity and the subsequent period of huge cosmic inflation at the beginning of the universe. However, if time did not start then, there are plausible alternative explanations (and new ones can be created in the course of future scientific processes). For instance, in the beginning of this universe, there may have been no point of singularity from which everything began, but rather

40 For an overview of alternative views, for instance those developed by Kant, Hegel, various critical theorists and American pragmatists such as Peirce and James, see Zachary Stein, "Beyond Nature and Humanity. Reflections on the Emergence and Purposes of Metatheories," in Metatheory for the Twenty-First Century: Critical Realism and Integral Theory in Dialogue, ed. Roy Bhaskar, Sean Esbjorn-Hargens, Nicholas Hedlund \& Mervyn Hartwig (London: Routledge, 2015), 35-68. some continuity from a predecessor universe. ${ }^{41}$ There are also many other reasons to think that time is real, continuous and non-finite, and also as global and irreversible. $^{42}$

Moreover, in this alternative story, our cosmos is singular and unique. There is only one universe at a time. While laws of physics may appear stable in the contemporary cooled-down universe, they are not immutable (if and when the relational structures change, so do laws). Causation, emergence and change are real. Everything is historical and evolving. Hence, physics and chemistry could well learn a few things from geology, life sciences and human sciences. ${ }^{43}$ Moreover, emergent layers such as conscious experience, agency, will and intentions are real and causally efficacious.

41 "If the singularity is absent, then the sufficient reason for choices of initial conditions and laws may lie in the world before the big bang." Roberto M. Unger and Lee Smolin, The Singular Universe and the Reality of Time (Cambridge: Cambridge University Press, 2015), 402.

42 The preferred cosmic time is not absolute (like it was for Newton) but relational. In a relational spacetime theory space is dependent on the relations between bodies; and time is dependent on events and processes. The preferred cosmic time is determined through the shape dynamics of the whole. Shape dynamics is an approach that has advanced during the 2010s and has a physical arrow of time due to the growth of complexity and the dynamical storage of locally accessible records of the past. Julian Barbour, Tim Koslowski and Flavio Mercati, "Identification of a Gravitational Arrow of Time," Physical review letters 113, no. 18 (2014). 181101. Cosmic time in this sense is consistent with the relativity of simultaneity in any local regions of spacetime. Unger and Smolin, The Singular Universe, 188, 420-1 [note 41]. Carlo Rovelli accepts that it is possible to distinguish the time that guides the rhythm of processes from a real universal time, and thus writes that "the point of view of Smolin, Ellis and Maroun is defensible". Rovelli, however, accuses Smolin of forcing the world to adapt to our intuition and contrasts that with "what we have discovered about the world". This is a petitio principii, however. The question that remain open is: what is it that we have discovered about the world? Carlo Rovelli, The Order of Time (London: Allen Lane, 2018), 190-1, n.14.

43 See Unger and Smolin, The Singular Universe [note 41]. 


\section{Account 1:}

\section{Meaninglessness and illusions prevail}

- Bï Bang: original singularity, possibly coming out of nothing, was also the beginning of time.

- The Big Bang itself is a meaningless and arbitrary event

- numerous black holes produce new universes $\rightarrow$ multiverse/Darwinism

- alternatively the universe may have emerged from nothing at all, due to arbitrary quantum effects

- Cosmos is indifferent or hostile to us humans.

- Ultimately time and causation are illusions; and agency is illusionary, redundant or marginal.

\section{Account 2: Reality involves life, consciousness and active agency}

There is only one universe at a time; reasons for the choices of initial conditions and laws lie in the world before the big bang.

- Time, causation, emergence and change are real; making also life possible.

- Cosmos is hospitable to life, although interpretations about the meaning and extent of this hospitality vary.

- Emergent layers such as conscious experience, agency, will and intentions are also real and causally efficacious.

Table 2: Contrastive accounts about the beginning and nature of cosmos

Life is not only real but it has generated new emergent powers on Earth and possibly elsewhere. Cosmologists have come to realise that complexity, life and billions of years of evolution in stable environment require very specific circumstances. For instance, all four basic forces of nature are in many ways implicated in the life story. Changing the strength of any of them, even by a small amount, could render the universe sterile. To give a more specific example, if certain very specific nuclear resonances in the nuclear physics of carbons were a little different, then the heavier elements could not build up in the interiors of red giant stars. The universe would contain only hydrogen and helium, and life would be impossible. The list is long. ${ }^{44}$

Overall, our singular and unique cosmos seems hospitable to life, although interpretations about the meaning and extent of this hospitality vary. ${ }^{45} \mathrm{~A}$

44 See e.g. Paul Davies, The Goldilocks Enigma: Why is the Universe Just Right for Life? (London: Allen Lane, 2006), 15171; or Martin Rees, Our Cosmic Habitat (Princeton: Princeton University Press, 2017).

45 Interestingly, Unger and Smolin, The Singular Universe, 531-2 [note 41] disagree about the extent to which the universe can be seen as hospitable to us. They agree that mostly nature is plausible alternative storyline about the future of the cosmos revolves around life and its possibilities rather than death. This account does not exclude individual death or the possibility of a collective catastrophe, but it stresses reflexivity about the poetic aspect of catastrophe-stories. The Greek word katastrophe meant "to overturn" or "turn upside down". In dramas, the catastrophe is the final resolution or climax in a poem or narrative plot, which brings the piece to a close. Although the word "catastrophe" has come to be associated with tragic endings rather than with happy ones, in a comedy the climax is a happy ending. It is only in tragedy that the climax of the story means

indifferent about us; that each individual is going to die; and that reverence for the universe is unhealthy power worship. Smolin stresses, nonetheless that their "natural philosophy" is also a bearer of good news. Neither we nor the universe is computational and our experiences accord with the nature of reality. We are part of the whole of nature and cosmos. Christian de Duve in turn shares the agnosticism of Unger and Smolin and yet argues that "available clues support the assumption that our universe is such that generation of life was obligatory, probably in many sites and at many times". Our universe is "pregnant with life". Christian De Duve, "How Biofriendly is Our Universe?," in Fitness of the Cosmos for Life: Biochemistry and Fine-Tuning, ed. John D. Barrow et.al. (Cambridge: Cambridge University Press, 2008), 194-5. 
the death of the hero (possibly together with many others). What is also important is that tragedy has a future-oriented purpose. The unexpected discoveries and sudden turns can generate a purifying or clarifying katharsis among the audience ${ }^{46}$, perhaps even some metaphysical comfort through experiencing human sacrifice in $\operatorname{art}^{47}$. Katharsis can thus be seen as a form of comfort; correction to excessive emotions such as pity or fear; or restoration of psychic health.

Comedy is life- and future-oriented. Comedy can be understood as the mythos of spring: the story of a new, better society replacing the old, absurd one. In comedy, there can be misunderstandings, illusions and actions with unforeseen consequences and some characters can also be represented in satirical light, but in the end things tend to turn out fine. Moreover, tragedies and comedies can also be mixed in various ways. ${ }^{48}$ Although nothing truly terrible happens in a tragicomedy, the end often involves unfulfilled desires and tragic feelings of the impossibility of a fully happy ending. This may bring tears - perhaps in the midst of laughter - to the eyes of the spectator. For these reasons, comedy is perhaps the most humane of the three main genres of narratives and plays. It involves the likelihood of a happy ending, but does not exclude the possibility of unfulfilled desires or tragic outcomes. ${ }^{49}$

46 Aristotle was of the opinion that tragedy must be simple and thus a well-constructed plot involves only a single catastrophe. "In the second rank comes the kind of tragedy which some place first. Like the Odyssey, it has double threat or plot, and also an opposite catastrophe for the good and the bad." Aristotle, Poetics, intro by Francis Fergusson (New York: Hill \& Wang, 1961), XIII, 77.

47 This was early Nietzsche's interpretation of Greek tragedy, which he proposed as a solution to the question "how can we overcome nihilism?". See Julian Young, The Death of God and the Meaning of Life (London: Routledge, 2003), 44-56.

48 See Riikka Kuusisto, “Comparing IR Plots: Dismal Tragedies, Exuberant Romances, Hopeful Comedies and Cynical Satires," International Politics 55, no. 2 (2018), 160-176.

49 I compare different possible story-lines concerning the future of global political economy and security in Heikki Patomäki,
Consider for instance internal and cosmic planetary catastrophes (violent earthquakes or volcanic eruptions, major asteroid or comet impacts) that seem to threaten our future. These are rare phenomena and their risks can be addressed by means of future-oriented planetary co-operation. Over time, our technological and organizational capacities to tackle these and other dangers will increase.

The danger of self-destruction in the course of the 21 st century seems more serious, for instance by means of weapons of mass destruction or ecological collapse. The possibility of a tragic global military catastrophe is real and appears once again, after the end of the Cold War, increasingly likely. Disintegrative tendencies and processes of conflict-escalation prevail due to the current constellation of forces in global political economy. They may be gradually assembling conditions for an ever bigger crisis - or a fullscale global catastrophe. Yet there is also a rational tendential direction to world history, more firmly based than contingent events and processes. ${ }^{50}$

The rational tendential direction is grounded in collective human learning. Three elements of rationality constitute the tendential directionality of world history. The first is truth, involving criticism of falsehoods and attitudes that sustain falsehoods. The second concerns overcoming contradictions through collective action and common institutions. Lastly, the third involves normative universalizability and our capacity to resolve social conflicts. Transformations toward a rational tendential direction is not automatic, it is realized through transformative praxis, which depends among other things upon the rationality of participating actors. The minimal meaning of rationality is openness to reason and learning.

The Political Economy of Global Security: War, Future Crises and Changes in Global Governance (London: Routledge, 2008), 217-21.

50 See Heikki Patomäki, Disintegrative Tendencies in Global Political Economy: Exits and Conflicts (London and New York: Routledge, 2018). 


\section{Preferred storyline 1: tragedy (end)}

- The story is basically the same epic tragedy without heroes at all scales of time.

- tragedy without katharsis

- A possible interpretation of katharsis: some (desperate) metaphysical comfort through experiencing human sacrifice in art (as in early Nietzsche).

- The sense of tragedy is typically combined with a Whig history about inevitable progress to the present (a typical story involves instrumentalist accounts of science, rationality as optimization, hedonism, and consumerism).

- Ultimate end in death.

\section{Preferred storyline 2: (tragi)comedy}

- Explanations of different outcomes, episodes and processes call for different plots and their combinations.

- Katharsis can be seen as a form of comfort; correction to excessive emotions such as pity or fear; or restoration of mental and social health.

- Tragicomedy: contingent developments, the end often involves unfulfilled desires and sense of impossibility of a fully happy ending.

- Comedy is humane because it involves the possibility of happy ending, but does not exclude tragic outcomes or unfulfilled desires.

- History is open, stories continue.

Table 3: Ideal-typical contrastive plots (mythos)

Once context-specific learning has occurred and a reasonable concrete direction set, the next logical step is the process of constructing transformative agency and building better common institutions to transform conflicts and tackle common problems. ${ }^{51}$

Our cultural evolution has created also other problems. Since the industrial revolution, human activities have affected biosphere and climate on a planetary scale. So far, the consequences have been negative, as shown by the mass-extinction of species and anthropogenic global warming. Yet the role of humanity may well be more life promoting and ethical in the future. A global climate regime has been in the making for a quarter of a century now. The flaws and deficiencies of the Kyoto Protocol and Paris UNFCCC Agreement notwithstanding, the gradual and troubled evolvement of climate governance indicates how the futurized nature of the present is changing. Reflexive self-regulation occurs through increased knowledge about the way natural and social systems work and

51 Patomäki, Disintegrative Tendencies, 116-27 [note 50]; see also Heikki Patomäki, "Emancipation from Violence through Global Law and Institutions: A Post-Deutschian Perspective," in Pacifism, ed. Johan Kustermans, Timothy Sauer, Didier Lootens and Barbara Segaert (Palgrave MacMillan: London, 2019). generate effects, not only now, but also in the future. ${ }^{52}$ Global climate governance is an attempt at reflexive self-regulation that consciously aims at homeostasis by regulating the planetary environment. The aim is to maintain a relatively constant temperature to counter the effects of greenhouse gases. This process will take time; a lot depends on the timing of adequate responses.

While constrained by real natural processes and social structures, the planetary future does not just happen but becomes increasingly something that various actors - including "we", whoever this we may refer to - make of it. There is also a deeper, a more cosmic aspect to this transformation. James Lovelock developed a controversial hypothesis in the 1960s and 1970s according to which the systems of life form a complex interacting system that maintains itself in the long run, through homeostatic feedback loops, lifefriendly climatic and biogeochemical conditions on

52 For a general account about how the futurized nature of the present is changing, see Heikki Patomäki "On the Complexities of Time and Temporality: Implications for World History and Global Futures," Australian Journal of Politics and History 57, no. 3 (2011), 339-352. 
Earth. ${ }^{53}$ However, both Gaian (negative) and non-Gaian (positive) feedbacks are likely to evolve in response to global warming. Hence, there is no automatic homeostasis, at least not in the scale of $10^{2}$ of years or less. ${ }^{54}$ If there is to be homeostasis, it must be created by means of conscious, future-oriented interventions into the ways in which our socio-economic systems work and are shaping Earth's climate and biosphere.

We humans have come to be deeply involved in Earth's future developments. Earth has nurtured life for a long time, continuously for more than three billion years. In a sense, the planet is now becoming conscious of itself through the gradual rise of human reflexive self-regulation aiming at maintaining lifefriendly climatic and biogeochemical conditions. What is more, reflexive self-regulation may contribute to improving the underlying social conditions of ethicopolitical learning. Collective learning reflexively shaping our common planetary conditions and the direction of world history as a whole can mean, among other things, that the sphere of human freedom is gradually widening - a process that may have much wider significance. The degree of freedom can be increased by replacing particular unnecessary and often misrepresented causal sources of determination with more wanted, needed and better-understood sources of causal determination, classically implying attempts to increase one's autonomy as self-determination. ${ }^{55}$ These are steps in "the long march of mankind toward its unity and better control of its own fate" ${ }^{56}$.

From the point of view of grand narratives, what

53 James Lovelock, "Gaia as seen through the Atmosphere," Atmospheric Environment 6, no. 8 (1972): 579-80; see also James Lovelock, "Hands Up for the Gaia Hypothesis," Nature 344 (1990), 100-2.

54 James Kirchner, "The Gaia Hypothesis: Fact, Theory, and Wishful Thinking," Climatic Change 52, no. 4 (2002), 391-408.

55 Bhaskar, Scientific Realism and Human Emancipation, 115 [note 32].

56 In the words of the Keynesian economist Robert Triffin, Our International Monetary System: Yesterday, Today, and Tomorrow (New York: Random House, 1968), 179. is interesting is the possibility that emergent layers of life and culture may gradually assume an increasingly important role in the process of cosmic evolution. Biological reality is multi-layered, hierarchically organized and involves interdependent functional synergies and higher-level controls, making purposive behaviour and, ultimately, also culture and consciousness possible. Complex systems of life have shaped the chemical composition and development of planet Earth for more than three billion years, setting it to a current path of development that is systematically off its non-living physical state of existence. The Earth is blue because it is teeming with life.

By cautiously generalising from the experiences of the Earth, it is conceivable that in the future life and consciousness will play a (co-)formative role in our galaxy and possibly even in the universe as a whole. From this perspective, British-born theoretical physicist and mathematician Freeman Dyson has proposed a vision that is best read as a plausible counter-hypothesis to the heat-death scenario:

The greening of the galaxy will become an irreversible process. [...] The expansion of life over the universe is a beginning, not an end. At the same time as life is extending its habitat quantitatively, it will also be changing and evolving qualitatively into new dimensions of mind and spirit that we cannot now imagine. ${ }^{57}$

This scenario of the greening of the galaxy sets a future project for humanity; the expansion of life and culture into space may be one of the chief tasks awaiting humankind. There may be other sentient and conscious beings, but even in that case, the greening of the galaxy would occur through cultural and technological means in a post-biological universe..$^{58}$ This implies that the future of cosmos is not only about

57 Freeman Dyson, Disturbing the Universe (New York: Basic Books, 1979), 236-7.

58 Steven J. Dick, "The Postbiological Universe and Our Future in Space," Futures 41, no. 8 (2009), 578-80. 
There is no alternative (TINA)

- Skepticism, combined with the reduction of the necessary and the possible to the actual ('actualism'), generates 'there is no alternative' thinking •

o this is also the origin of Whig-histories

- Reductionism suggests either value subjectivism (though individuals may behave morally for whatever arbitrary reasons) or outright moral nihilism.

- Reductionism turned into ideology of markets and established order of things (of TINA, there is no alternative).

- Life and society are about competition: Darwinism - market-society - capitalism.

- Some improvements may be possible, but only within the prevailing institutional liberalcapitalist order.

\section{Emancipatory transformations are possible}

The rational tendential direction of world history is grounded in collective human learning.

Three elements of rationality constitute the tendential directionality of world history:

1. Truth, involving criticism of falsehoods and attitudes that sustain falsehoods.

2. Normative universalizability and our capacity to resolve social conflicts.

3. Overcoming lacks, contradictions etc through collective action and common institutions (revising old building \& new institutions).

- The possibility of development of new cooperative capacities, needs and ethico-political horizons ("new dimensions of mind and spirit that we cannot now imagine").

Table 4: Ideal-typical ethico-political differences

expansion of life but also about society and culture, about ethics and politics. More than that, structures and processes at that level of reality can create new dimensions of mind and spirit, through collective learning of humankind (and other species).

Pragmatism and critical scientific realism encourage cosmic hopefulness, thereby facilitating scientific learning and progress. Astrobiology will be a key area of learning in the next few decades and centuries. We are likely to learn much more about the conditions and determinants of life in the universe. ${ }^{59}$ This learning will shape our future-scenarios and assessments of their plausibility. Whereas the prevailing mythologeme of liberal-capitalist societies is characteristically associated with parametric (environment is seen as fixed in relation to one's individual choices) and strategic modes of consciousness (other subjects are recognised only as strategic players and the point remains to optimise under constraints) ${ }^{60}$; in this

59 Steven J. Dick, Astrobiology, Discovery, and Societal Impact (Cambridge: Cambridge University Press, 2018).

60 For these modes, see Jon Elster, Logic and Society (Chichester: John Wiley \& Sons, 1978), ch 5. alternative mythologeme, actors:

- recognise each other as equal subjects positioned in social relations.

- are capable of recognising social ills and contradictions at the level of wholes.

- and are capable of organizing collective actions and building common institutions to absent ills and overcome contradictions.

Cosmic hopefulness encourages attempts to build trust, solidarity and ethico-political commitments. Successful organization of collective action requires communication to feed the development of trust and solidarity. Success in these endeavours is contingent on agency and eco-socio-historical conditions. Because of contingency, success is not guaranteed: negative outcomes are possible. In this alternative mythologem, types of plots can be combined in many ways to understand particular episodes or processes. A happy ending is in no way guaranteed but achievable, even if it may involve unfulfilled desires and tragic feelings of loss. Hopefulness can exhibit itself at different scales of time. Some outcomes may be negative, tragic and 
even terminal in relation to a particular process or processes; while wider processes will always persist. The more a hopeful story stresses the negative, tragic and terminal phases, the closer it gets to Christian and Marxian eschatology; and thereby it becomes more liable to accepting unnecessary suffering and violence. ${ }^{61}$

\section{Analysing and assessing the Big History storyline}

At first look, the current version of $\mathrm{BH}$ appears consistent with the life- and learning-oriented storyline. David Christian's grand narrative about our origins is meant to stand in for the role played by mythical narratives in early human societies. ${ }^{62}$ The idea is that deep stories are important in establishing meaning and identity. Ethical and political projects derive their motivation from the sense they render to our lives. The explicit purpose of $\mathrm{BH}$ is to help to establish a widespread awareness of belonging to a planetary whole. ${ }^{63}$ The hope is that the modern cosmic story of our origins will forge a global we-feeling and

61 For example, Wagar's A Short History of the Future ( $3^{\text {rd }}$ edition, Chicago: Chicago University Press, 1999) involves a nuclear war in the 2040s and the death of seven billion people. The scenario is based on the assumption that only a tragic global catastrophe can spell an end to the system of nation-states and capitalist world economy and lead to global-democratic transformation. Ironically, the nuclear war of 2044 means a happy ending to the process of global warming. In this story, transformative agency lies in a world political party. In the 2050s, there is a debate in the party between the pluralists, preferring non-violent methods and the possibility of staying outside the World Commonwealth, and the Leninists. The Leninists carry the day. The world is united under a democratic-socialist world state, but at the expense of an additional three million casualties.

62 World history, world systems theory and related attempts have preceded and paralleled Big History in Christian's sense. For a brief history of Big History, see David Christian, "What is Big History?," Journal of Big History 1, No:1 (2018), 4-19 (available at http://dx.doi.org/10.22339/jbh.v1i1.2241).

63 Already H.G.Wells's Outline of History (originally published in 1920) was explicitly motivated by a desire to unify humanity in terms of a common planetary history located in a cosmic setting. cooperation in the world plagued by global problems. The bulk of this narrative concerns increasing complexity on the life-friendly planet Earth. New properties and powers come to being through major turning points. BH not only frames world history in cosmic terms and imagines a future world community, but it is also systematically critical of Eurocentrism and other forms of centrism. By evoking innovative myths about shared human existence and destiny, $\mathrm{BH}$ helps to articulate a rising global imaginary for transformative and progressive politics in the 21 st century. ${ }^{64} \mathrm{BH}$ appears thus committed to a transformative planetary vision and stresses the role of biological and cultural evolution and increasing complexity.

However, a closer look reveals ambiguities. BH contains some elements from both storylines - and not in an entirely unproblematic way. This raises the question of whether it is possible that the $\mathrm{BH}$ tale could turn out to be counterproductive. At the deepest level, Christian and his co-authors seem committed to the standard version of the Big Bang cosmology as the last word of science so far, even if they are agnostic about the details of the origins of the universe: "We don't really know what [the universe] came out of or if anything existed before the universe". What is more certain is that when the universe emerged from "a vast foam of energy, it was extremely simple". ${ }^{65}$ These reservations and qualifications notwithstanding, Christian, Brown and other $\mathrm{BH}$ authors affirm the notion that the original singularity, possibly coming out of nothing, was followed by cosmic inflation. The wider cosmic context of the Big Bang is a multiverse

64 Heikki Patomäki, and Manfred Seger, "Social Imaginaries and Big History: Towards a New Planetary Consciousness?," Futures 42, no. 10 (2010). 1056-63; Heikki Patomäki, "On the Possibility of a Global Political Community: The Enigma of 'Small Local Differences' within Humanity," Protosociology. An International Journal of Interdisciplinary Research 33, no. 1 (2017), 93-127.

65 David Christian, Origin Story: A Big History of Everything (London: Allen Lane, 2018), 11. 
or Darwinist selection of universes. ${ }^{66}$ This is the first tier of the liberal-capitalist myth.

For non-experts in cosmology, it is of course reasonable to rely on the currently prevailing scientific opinion, even when it is non-consensual. It is beyond reasonable doubt that the early universe was radically smaller and much simpler than the current universe. Reliance on the standard Big Bang theory satisfies some requirements of a reasonable appeal to scientific authority ${ }^{67}$ However, claims about the beginning of time, multiverse and Darwinist selection of universes are speculative. Whatever evidence there may be is usually circumstantial and indirect at best. The hypothesis of cosmic inflation seems to accord well with the evidence (especially background radiation), but rival hypotheses can explain the same evidence. ${ }^{68}$ Moreover, we know that also evidence-based scientific theories are open to change and that scientific expert opinion can be driven by sense-making and storytelling. While it goes without saying that we cannot settle scientific disputes at the philosophical or mythological level only, differences at that level matter, especially in contexts where evidence is ambiguous and there are competing hypotheses, theories and speculations.

$\mathrm{BH}$ is an impressive achievement, and yet it

66 Christian, Maps of Time, 22-25 [note 1]; Christian, Origin Story, 20-5 [note 64]; Christian, Brown and Benjamin, Big History, 14-20 [note 1]; Cynthia Stokes Brown, Big History: From the Big Bang to the Present (New York: The New Press, 2007), 4-7.

67 Out of the six requirements specified by Douglas Walton, only two seem problematical, namely consistency ("is the claim in question consistent with what other experts assert?") and evidence ("is expert X's assertion based on solid evidence?"). In the frontiers of cosmology, experts tend to disagree, often wildly so, and evidence is typically circumstantial and strongly theory-laden, often based on mere (other) theories and mathematical models. Douglas Walton, Informal Logic. A Pragmatic Approach (Second edition, Cambridge: Cambridge University Press), 217222.

68 See Unger and Lee Smolin, The Singular Universe [note 41], 402. can be argued that the theoretical and practical commitments of $\mathrm{BH}$ are not entirely consistent. Firstly, BH is in important part motivated by the "sense of disorientation, division and directionless" that characterises our modern world. ${ }^{69} \mathrm{BH}$ criticizes excessive specialisation and fragmentation of sciences and humanities. Christian writes daringly about "a return to the goal of a unified understanding of reality, in place of the fragmented visions that dominate modern education and scholarship". ${ }^{70}$ However, many prevailing theories and speculations about the origins and nature of the universe stem from theories that contradict the views and aims of $\mathrm{BH}$. In its current mainstream form, science is habitually premised on reductionism. This is evident for instance in numerous attempts to develop a theory of everything ("a set of equations capable of describing all phenomena that have been observed, or that will ever be observed"). ${ }^{71}$ What is more, the abstract logical time of mathematical theories in fields ranging from physics to economics turn time into a quasi-spatial dimension and represent reality as atemporal or at least ahistorical.

Second, and perhaps more importantly, $\mathrm{BH}$, as articulated so far, seems to share several end-indeath scenarios with the liberal-capitalist worldview. Entropy will increase and space expand until a few "lonely beacons of light will find themselves in a galactic graveyard"72 - and finally these lonely beacons will perish too. The end of our solar system will come much sooner and well before that, the Earth will become uninhabitable. "It will be as barren as the Moon is today" "73 . The account of possible and likely human futures at $10^{2}$ scale of time is more balanced. Colonization of other worlds - if we ever succeed reaching other solar systems - may make humanity

69 Christian, Origin Story, 8 [note 65].

70 Christian, "What is Big History?" 4 [note 62].

71 For a criticism of this reductionist programme by well-known physicists, see R. B. Laughlin \& David Pines, "The Theory of Everything," PNAS 97, no:1 (2000), 28-31.

72 Christian, Maps of Time, 489 [note 1].

73 Christian, Maps of Time, 487 [note 1]. 
less dependent on Earth. Meanwhile, while it is "easy to imagine catastrophic scenarios brought about by nuclear or biological warfare, or ecological disaster, or perhaps even a collision with a large asteroid", also a progressive outcome of history is possible. "It is the in-between scenarios that are both most likely and most difficult to imagine." ${ }^{.74}$ Even a hesitant commitment to the unfounded cosmic mythologeme of meaninglessness and inevitable end-in-death can easily become counterproductive in relation to the ultimate aims of $\mathrm{BH}$.

Thirdly, at a practical and ideological level, the problem lies in the presumption that in spite of all the specialisation and fragmentation, science is on the side of an enlightened and progressive cosmopolitan vision. In reality science is interwoven with the global problems, both practically (e.g. as part of militaryindustrial complex or ecologically unsustainable systems of production and consumption) and ideologically (including through the propagation of mythologems that encourage consumerism and competitive behaviour) $)^{75}$. To use Thomas Kuhn's terminology, a typical scientist does "normal science", working within a settled - and typically empiricist - framework, leaving the conceptual, social and political framework unchallenged. The results of his or her work can easily be adapted to any technical purpose, including profit- or war-making. ${ }^{76}$ This is especially true in a world where the university has been repurposed in terms of success in global competition of corporations and states; usefulness

74 Christian, Maps of Time, 482 [note 1]; Christian, Origin Sto$r y, 289$ [note 65] formulates the same point in perhaps slightly less pessimistic terms and mentions, on 294, also the possibility of emergence of a "new world society that preserves the best of the Good Anthropocene".

75 Cosmic desperation associated with empiricist (positivist) doctrines encourages short-termism and technical-utilitarian orientation to the world, clearly against the point of Big History.

76 In his interesting book, Steve Fuller portrays Kuhn as the official philosopher of the US military-industrial complex. Steve Fuller, Kuhn vs. Popper: The Struggle for the Soul of Science (Thriplow: Icon Books, 2006), 32, 123. for money-making; and corporate-style efficiency. ${ }^{77}$ The repurposing of the university has deepened these problems. According to for example Martin Rees, a British cosmologist and Astronomer Royal, many plausible 21st century catastrophe-scenarios stem from scientific developments. "In the present century the dilemmas and threats will come from biology and computer science, as well as from physics." ${ }^{.78}$ Among other things, this raises the question whether ethical constraints should be set on science and whether science should be slowed down. An instrumentalist and acquiescent science should not be trusted uncritically, especially under the current political conditions.

Frederick Jameson has remarked that it seems easier nowadays to imagine the end of the world than the end of a particular social system, capitalism. ${ }^{79} \mathrm{BH}$ appears close to the mainstream also in this regard. Interpretations of recent and contemporary history reinforce constraints on imaginative capacities. The history of the Soviet Union, for instance, suggests "that overthrowing capitalism may be an extremely destructive project" and unlikely to succeed in its own aims (egalitarianism, ecological sustainability). While Christian is truly concerned about rising inequalities and the possibility of ecological destruction, he also assumes that inequalities will remain a problem as long as capitalism remains dominant. Moreover, inequalities can "generate conflicts that guarantee the

77 See for example James H. Mittelman, Implausible Dream. The World-Class University and Repurposing of Higher Education (Princeton, NJ: Princeton University Press, 2018); for a vision for the future, see Heikki Patomäki, "Repurposing the University in the 21st Century: Toward a Progressive Global Vision", Globalizations, 16 no.5 (2019), 751-762.

78 Rees, Our Final Century, 40 [note 26].

79 Fredrik Jameson, Archaeologies of the Future: The Desire Called Utopia and Other Science Fictions (London: Verso, 2005), 199. Unlike Christian, for instance Brown does not even mention capitalism in the context of her future-scenarios (although discusses capitalism in the historical part). With regard to the future, she focusses entirely on environmental questions abstracted away from political economy institutions; Brown, Big History, 230-46 [note 66]. 
eventual use of the destructive military technologies now available to us". ${ }^{80}$ The hope lies in mitigating some of the consequences of capitalism. Taxes and subsidies can be used to steer economic activities toward more sustainable directions. The living standards of subordinate classes may rise in even the world's poorest countries. Perhaps capitalist peace will prevail in the end. ${ }^{81}$ The argument seems to rely, after all, on economic growth.

I am not implying that $\mathrm{BH}$ must include a story about the end of capitalism and beginning of something that will replace it. That scenario would mean a commitment to Marxism or some other deep-structure social theory that believes in a compulsive, world-historical sequence of stages of social organization (perhaps following the mythical sequence of Armageddon $\rightarrow$ Millennium $\rightarrow$ New Jerusalem), with each stage representing a type of society from a closed list of possible frameworks (such as feudalism, capitalism and socialism). ${ }^{82}$ Rather $\mathrm{BH}$ should develop its understanding of historical development and change in terms of collective learning, transformative agency, experimentation and concrete utopias ${ }^{83}$.

The problem is that currently $\mathrm{BH}$ is rather cautious and ambivalent about the needed and desired ethico-political direction. Our current institutional arrangements are not the necessary outcomes of some

80 Christian, Maps of Time, 478-81 [note 1].

81 E.g. Erich Weede, "Economic Policy and International Security: Rent-Seeking, Free Trade, and Democratic Peace," European Journal of International Relations 1, no:4 (1995), 519-537.

82 For a strong criticism of the 'closed list of possible frameworks' thinking, see Robert Mangabeira Unger, Politics: The Central Texts: Theory against Fate, ed. and intro. by Zhiyuan Cui, (London: Verso, 1997), 33-41 et.passim.

83 Ernst Bloch introduced the concept of concrete utopia in his The Principle of Hope that was published successively in three volumes in 1954, 1955, and 1959. The term has been adopted by various critical theorists. The term u-topia is a bit misleading, however, as it means a place nowhere. A positive, hope-inspiring counterpart to dystopia is actually eutopia, which could be translated as 'a good place' (or: a place enabling human flourishing). unspecified organizational, economic, or psychological constraints. Rather new ethical and political are likely to emerge in response to the problems that have emerged because of the acceleration of our cultural evolution. How will the future then turn out? Many key questions are pushed aside or left unanswered. Will production be robotized and automatized entirely; or will production be based on free voluntary association of citizens, perhaps serving purposes we cannot anticipate now? Does money or property continue to exist? ${ }^{84}$ How will increasing longevity and our moral learning shape intimate relations ${ }^{85}$ Will the ever-more sophisticated technologies be put in the service of some dystopian purposes or do they open up new possibilities for democratic participation? What about the future of war and violence? If the current trends continue, war and violence will have become virtually absent already in the 2200s, if not sooner. ${ }^{86}$ Can nuclear weapons and other weapons of mass destruction be abolished? Will there be any need for people specializing in violence? Will geopolitical states be replaced by a new functionalist system or by world state - or rather, will all states wither away? ${ }^{87}$

84 For an example of a serious contemporary proposal to make property conditional, temporary and democratic, see Unger, $P_{o-}$ litics, esp. 306-95 [note 82]. Unger has been an influential politician in Brazil. Also the idea that there is no money resonates with popular imagination, even if unnoticed in mainstream politics. For instance, for a discussion about the ambiguous politics of the post-capitalist Star Trek, see Dan Hassler-Forest, Science Fiction, Fantasy, and Politics: Transmedia World-Building Beyond Capitalism (London: Rowman \& Littlefield, 2016), 47-66.

85 For some speculations, see e.g. Wagar, A Short History [note 61]; James L. Halpern, The First Immortal: A Novel of the Future (New York: Random House, 1998).

86 The claim about the declining role of violence is nowadays most often associated with Steven Pinker, The Better Angels of Our Nature: The Decline of Violence in History and Its Causes (London: Allen Lane, 2011). About actual and potential countertendencies, see Patomäki, Disintegrative Tendencies [note 50].

87 Christian, Origin Story, 301 [note 65] mentions this question but does not discuss it. For discussions from a variety of perspectives, see Cooperation \& Conflict special issue, with intro: Mathias Albert et al., "Introduction: World State Futures," Cooperation \& Conflict 47, no. 2 (2012), 145-56. 
Concrete eutopias establish a direction and normative telos to history. At any given worldhistorical moment, there are some possible rational directions of world history. Over time, there will be a succession of such moments. Setting a direction is a matter of dialectical discussions and debates, always occurring under concrete world-historical circumstances. This is what the openness of world history means. Any claim about rational tendential directionality of world history has to be understood as a dialectical argument within the meaningful human sphere ${ }^{88}$ Rationality cannot be confined to any particular agents or collective category. Once contextspecific learning has taken place and a reasonable direction been set, the next logical step is the process of constructing transformative agency. The question of transformative global agency concerns rationality and developments that may take decades. The making of a collective agency is a process of active and reflexive engagement within the world in which we seek to achieve the unity of theory and practice in practice. ${ }^{89}$

Transformative praxis has to be processual, developmental and directional, involving political programmes specifying aims and concrete eutopias. Its organisational forms must be compatible with these requirements. The transformative praxis itself can be transformed on the basis of past experiences and criticism of them. In the globalised world of the $21^{\text {st }}$ century, there is a quest for new forms of agency such as world political party. ${ }^{90}$ While a rational direction

88 See Heikki Patomäki, "On the Dialectics of Global Governance in the 21st Century: A Polanyian Double Movement?," Globalizations 11, no. 5 (2014). 751-68; Patomäki, Disintegrative Tendencies, 116-27 [note 50].

89 Roy Bhaskar, Dialectic: The Pulse of Freedom (London: Verso, 1993), 8, 158-61.

90 Key questions of a global party-formation include: how would it be possible to combine (i) the capacity to establish an overall, binding direction to the activities of the party with (ii) a democratic process of will-formation that also maximises its learning capacity? Heikki Patomäki, "Towards Global Political Parties," Ethics \& Global Politics 4 no. 2 (2011), 81-102, freely available at http://www.ethicsandglobalpolitics.net/index.php/ can be set, debated and disputed, world history is open-ended and, because of our capacity to create something new, unanticipatable. For all imaginable purposes and beyond, humanity's time for its desires and projects can be virtually infinite. World history is just about to begin.

As H.G.Wells put it, according with the spirit of pragmatism, critical realism and visionaries such as Freeman Dyson: "The past is but the beginning of a beginning, and all that is and has been is but the twilight of the dawn". A story portraying the present as "the twilight of the dawn" is more hopeful and inspirational than a gloomy story about us humans marching toward some inevitable end at some scale of time. As Wells proclaimed: "All this world is heavy with the promise of greater things." ${ }^{\prime 1}$

\section{Conclusions}

In this paper, I have argued that contemporary science is consistent with at least two different storylines. The basic mythologems of contemporary liberal-capitalist societies - verging on cosmic desperation - tend to be in line with market globalism ${ }^{92}$. They are, however, instrumentalist and can easily submit to any demands to provide means for some ends (or be simply indifferent about the use of scientific knowledge). The prevailing narrative is largely and in most time-scales oriented toward a tragic end, thus undermining hope for collective learning and progress. Empiricist science tends to feed into a sense

egp/article/view/7334; and for a call for such a party, see Heikki Patomäki, "A World Political Party: The Time Has Come", GTI essay, February 2019, available at https://www.greattransition. org/ publication/world-political-party.

91 H. G. Wells, The Discovery of the Future (New York: B.W. Huebsch, 1913), 60, https://catalog.hathitrust.org/Record/001188090.

92 For the concept of market globalism, see Manfred Steger, Globalisms: The Great Ideological Struggle of the Twenty-First Century (3rd ed. Lanham, MD: Rowman \& Littlefield, 2009). 
of disorientation, division and directionless. Attitudes can vary from indifference to reality to outright scepticism and escapism to fantasy-worlds such as imagined parallel quantum worlds (or sport, soap and nostalgia). Freedom in this mythologeme consists of unimpeded exercise of optimizing behaviour. Consumerism results from the absence of hope and good life.

The alternative storyline, revolving around life and learning and involving cosmic hopefulness, starts from the idea that time, space, causation, emergence and change are real. Cosmos is historical and evolving, and it is also hospitable to life. Over time, life has generated new emergent powers on Earth; it may have done so also elsewhere in the universe. A key point is that emergent cultural layers such as conscious experience, agency, will and intentions are real and causally efficacious. This makes scientific practices and transformative ethico-political activities possible. The rational tendential direction of world-history is grounded in our collective human learning, making it possible to solve problems, absent ills and overcome contradictions by means of collective actions and by building better common institutions.

I have argued above that the storyline of Big History is ambiguous in problematic ways, while not all complexities of our stories are undesirable. Explanations of different outcomes, episodes and processes call for different plots and their combinations. The point is that the life-oriented storyline involves also the possibility of happy endings and new beginnings. It cultivates the idea that the past as we know it may be just the beginning of a beginning. In this epic story involving humankind, the Earth as a whole is now becoming conscious through the gradual rise of human reflexive self-regulation aiming at maintaining sustainable life-friendly biogeochemical, climatic and socio-economic conditions. What is more, reflexive self-regulation may contribute to improving the underlying social conditions of our ethico-political learning. The conditions of free development of any particular human being are social and thus involve deep interconnectedness. Collective learning - shaping reflexively our common planetary conditions and the direction of world history as a whole - can mean, among other things, that the sphere of human freedom is gradually widening. This process of human emancipation can have cosmic significance, also because the expansion of life and culture into space may be a task awaiting humanity. 
